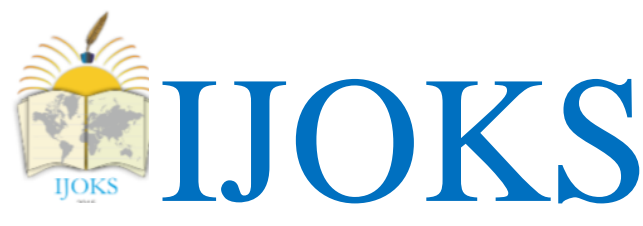

International Journal of Kurdish Studies

(ISSN:2149-2751)

4 (1), pp. $273-287$

http://www.ijoks.com

\title{
Barış Çalışmalarında Alternatif Bir Güzergah: Sembol ve Sembolizmin Politik Kullanımı ${ }^{1}$
}

Safiye ATEŞ (DURÇ) $)^{2}$

Received: Dec 01, 2017 Reviewed: Dec 20, 2017 Accepted: Jan 12, 2018

\section{$\ddot{\mathbf{O} z}$}

Çağdaş barış çalışmaları, uzun yıllar boyunca makro (amaçlı) meseleler üzerinden yürümüştür. Silahsızlan(dır)ma, sivilleşme, paramiliterlerin topluma yeniden entegrasyonu ve hukuksal bazı metinler olarak maddeleştirebileceğimiz bu meseleler; çatışmanın sebepleri, çatışmanın sürdürülebilirliğini mümkün kılan araçların toplanması ve barışmanın teknik ve hukuksal mekanizmalarının oluşturulması temelinde ele alınmaktadır. Şiddetin sona ermesi veya sönümlenmesi için öncelikle bu makro konuların halledilmesi gerekir. Ancak kültürel şiddeti oluşturan ve ikincil konular olarak değerlendirilen sembol ve ritüellerin kullanımı da kesinlikle gözardı edilmemesi gereken bir konudur. Çünkü sembol ve sembolik eylemin siyasal kullanımı şiddetli çatışmayı toplumun en küçük birimine kadar taşır. Potansiyel şiddetin devam ettiği bir toplumsal alanda ise toplumsal barışın sürekli kılınması neredeyse imkansızlaşır.

Barış çalışmaları literatüründe özellikle 2000li yıllardan sonra sembol ve sembolizmin politik kullanımına dair önemli çalışmalar yayınlanmıştır. Bu çalışmalarla birlikte konuyla ilgilenen teorisyenler artık, sembollerin pozitif veya negatif anlamda barış süreçleri için kritik değere sahip olduğunun farkına varmıştır. Peki bu güzergahı alternatif bir güzergah olarak kabul edebilir miyiz? Sembol ve sembolizmin politik kullanımına dair temel tartışma eksenleri nelerdir? Bu çalışmada dünyadaki barış süreci örneklerinin yol göstericiliğinde yukarıdaki sorulara yanıt aranmaya çalışılacaktır.

Anahtar Kelimeler: Siyasal sembol, barış, kültürel şiddet, barış çalışmaları, sembolik çatışma

\footnotetext{
${ }^{1}$ Bu çalışma Ekim 2018'de Belek Antalya'da düzenlenen 2nd Eurasian Conference on Language \& Social Studies adlı konferansta sunulan tebliğin genișletilmiş halidir.

${ }^{2}$ Mardin Artuklu Üniversitesi Siyaset Bilimi ve Uluslararası İlişkiler bölümü araştırma görevlisi ve Ankara Üniversitesi Siyasal Bilgiler Fakültesi, Siyaset Bilimi Anabilim Dalı doktora öğrencisi. E-mail: safiye83@gmail.com
} 


\begin{abstract}
Contemporary peace studies have been laid emphasis on macro affairs for many years. These issues are disarmament, demilitarization, collective reintegration of paramilitaries and some legal texts. Also these technical and legal mechanisms are the main reasons of the conflict. So they need to be solved first for the end of the violence or for the damping of the violence. However, the use of symbols and rituals, which constitute cultural violence and are considered secondary issues, should certainly not be overlooked. Because the political use of symbols and symbolic action pushes violent conflict to the smallest unit of society. In a social context where potential violence continues, it is almost impossible to make social peace permanent.

Important studies on the political use of symbols and symbolism have been published in the literature of peace studies especially after 2000 years. Theorists who are interested in the subject together with these studies now realize that symbols have critical value for peace processes in the positive or negative sense. Can we consider this route as an alternative route? What are the main axes of discussion about the symbolic and symbolic use of symbols? In this study, we will try to find answers to the above questions in the guidance of peace process examples in the world.
\end{abstract}

Keywords: Political Symbol, peace, cultural violence, peace research, symbolic conflict

\title{
Recommended citation:
}

Ateş (Durç), S. (2018). Barış Çalışmalarında Alternatif Bir Güzergah: Sembol ve Sembolizmin Politik Kullanımı. International Journal of Kurdish Studies 4 (1), 273 -287, DOI:

\section{Giriş}

Yirminci yüzyılda barış çalışmaları, silahlı çatışmaların bitirilmesi amacıyla özellikle zorlu konulara odaklanmıştır. Bu konular sıcak çatışmanın sürdürülmesinin aracıları ve nedenleri olduğu için çözümlenmesi gereken birincil konular arasına girmektedir. Silahsızlanma, sivilleşme, yeniden entegrasyon ve belli bazı hukuki metinlerin hazırlanması olarak sıralayabileceğimiz bu birincil meseleler, barış süreçlerinde ve müzakerelerde derinlemesine tartışılmaktadır. Zorlu yapılarına rağmen çözüme yatkın olan bu konular, stratejik bazı müdahalelerle ve belli kurallar dahilinde görece kolay bir şekilde halledilebilir. Lakin barışma sadece teknik bir mesele değildir. Onu kültürel farklılıklardan ve kültürel şiddetten 
bağımsız bir durum olarak ele alamayız.

Kültürel hegemonya, kültürel şiddet ve bunların canlı tuttuğu yapısal şiddeti bugün çağdaş barış çalışmaları da kabul etmekte ve daha önce çoğunlukla teknik meseleler olarak değer gören barış süreçleri ve çatışmalar artık farklı bağlamlarda da incelenmektedir. Barış eğitimi ve barış gazeteciliği gibi alanların yanı sıra kültürel şiddeti görünür kılan sembol ve ritüellerin üretimi ve kullanımı da artık barış çalışmalarında kabul gören bir tartışma alanı olmaktadır. Kuzey İrlanda, Güney Afrika, İsrail-Filistin, Bosna-Hersek ve Kosova gibi birçok çatışma ve barış süreci örneği artık sembollerin politik kullanımı ve sembolik çatışma kuramı doğrultusunda ve bilimsel olarak ele alınmaktadır. Böylece literatüre de yeni ve üretken bilgiler dahil olmaktadır. Peki bu yeni tartışma alanını barış çalışmalarında alternatif bir güzergah olarak kabul edebilir miyiz? $\mathrm{Bu}$ temel soru eşliğinde ilerleyecek olan bu çalışmada disiplinin tarihsel arka planı ve kuramsal kavşakları aktarılıp, sembol ve sembolizmin politik kullanımına dair yapılan çalışmalar ve tartışmalar aktarılacaktır.

\section{Disiplinin Tarihsel Arka Planı}

Barış Çalışmaları veya Barış Araştırmaları adıyla bilinen disiplin, İkinci Dünya Savaşı sonrasında özellikle Çatışma Analizi ve Çözümü bilim dalı ile birlikte sosyal bilim alanında görünür olmaya başlamıştır. Yirminci yüzyılın ilk yarısında ulus devletler arasındaki silahlı çatışmaların sona erdirilmesi ve kalıcı barışın tesisine odaklanan barış çalışmaları, yine bu dönemlerde akademik kurumların inceleme alanlarına dahil olmuştur. $\mathrm{Bu}$ anlamda sunulabilecek ilk örnekler 1930'da kurulan Alman Barış Akademisi ve 1931'de Fransa'da Lyon Üniversitesi'nde açılan Uluslararası Teşkilatlar ve Barış Çalışmaları bilim dalıdır (Sandıklı ve Kaya, 2012). Ancak barış çalışmaları denince akla gelen ilk (ve hala etkin) 
akademik birimler 1950 'den sonra kurulmaya başlanmıştır. İkinci Dünya Savaşı ve muhakkak ki Birinci Dünya Savaşı birçok teorisyeni ve politikacıyı; uyuşmazlıkların çözülmesi ve barış anlaşmalarının objektif kriterler eşliğinde sonuçlandırılması için sistematik ve bilimsel çalışmalar yapmaya ya da yaptırmaya sevk etmiştir. Çünkü her iki dünya savaşı da şiddetin en kör halinin yaşandığı savaşlardır. İlişkisel olarak bu savaşlar aynı zamanda barışın ne kadar kıymetli bir durum olduğunu da gösteren en somut olaylardır. Barış çalışmalarının bir disiplin olarak bu dönemde aktifleşmesi de bu ilişkisel karşıtlıkla bağlantılıdır. Savaşın karşıtı olarak barış şeklinde formüle edebileceğimiz bu ilişkisel karşıtlık, bilimsel çalışmalara da yansımıştır. Nitekim 1960'ların sonuna kadar barış, literatürde savaş karşıtlığı üzerinden tartışılmıştır.

Barış araştırmalarının akademik bir disiplin olarak değer kazandığı dönem, daha önce bahsedildiği gibi İkinci Dünya Savaşı sonrası dönem; mekan ise ABD’dir. Burada söz konusu dönemde üniversite ve kolejlerde öğrenciler savaş karşıtı gösteriler yapmış (Akgül, 2016), şiddetin ortadan kaldırılması ve barış sesinin yükseltilmesi hususunda ABD kamuoyunda bir ortaklaşma yaşanmış ve Nazi baskılarından kaçan bilim adamları ciddi entelektüel katkılar (Yılmaz, 2006) sunmuşlardır. Bu ülkede barış çalışmalarına dair ilk kurumsal yapı ise $1948^{\prime}$ de Indiana'daki Manchester Koleji’nde ruhsal ve sosyal dönüşüm konusuna odaklanan bir program (Fahey, 2010) olmuştur.

Avrupa'da barış çalışmalarının başlaması ise 1960'ları bulmuştur. ABD'dekilere göre daha geç bir tarihte kurulmuş olsalar da bu kurumlar ve orada sürdürülen çalışmalar barış araştırmaları literatürünün büyük kısmının oluşmasını sağlamıştır. 1959'da Oslo Barış Araştırmaları Enstitüsü (Peace Research Institute Oslo-PRIO), 1966'da ise Stockholm Barış 
Araştırmaları Enstitüsü (Stockholm Peace Research Institute-SIPRI) kurulmuştur. Yine 1973 'te İngiltere'nin Bradford Üniversitesi'nde Adam Curle başkanlığında açılan Barış Çalışmaları Merkezi de bu alanda etkili çalışmalar yapan birimlerdendir. PRIO tarafindan 1964'ten beri basilan The Journal of Peace Research (Dungen ve Wittner, 2003) ve 1957'den beri yayın yapan The Journal of Conflict Resolution (Boulding, 1978), The International Journal of Peace Studies, Peace and Change ve International Journal of World Peace (Alger, 2007) bugün alanın en prestijli yayınlarındandır.

Görüldüğü üzere barışın, akademik kurumların çalışma alanı haline gelmesi neredeyse yetmiş y1llık bir geçmişe sahiptir. Kurulan birimler ve bu birimlerde yapılmış olan çalışmalar elbette ki barış çalışmaları literatürünün oluşmasında çok etkili olmuştur. Ancak bu literatür adına aktarılması gereken en önemli bilgi, akademik anlamda disiplinin odaklandığı temel meselelerdir. Bunlar aynı zamanda barış çalışmaları alanında hangi kuramsal kavşakların olduğunu da göstermektedir.

Söz konusu disiplin ilk dönemlerde savaşın sebep olduğu nicel meselelere odaklanmıştır. Quincy Wright, Lewis Fry Richardson ve Pitirim Aleksandrovich Sorokin bu alandaki ilk ve en önemli araştırmacılardır (Boulding, 1978). İkinci Dünya Savaşı'yla birlikte alandaki temel tartışma konuları nükleer savaş ve uluslararası çatışmalar olmuştur. Devletlerarası savaşların yarattığı yıkıcı etkileri durduracak yol ve yöntemlere (Mason, 2002) odaklanan barış çalışmaları, Soğuk Savaş'ın bitimine doğru ilgisini ulusların içine sızan etnik çatışmalara kaydırmıştır. Böylece disiplinin odaklandığı temel meseleler artık sadece savaş ya da çatışma halinin sebepleri değildir; etnik dinamikler ve aktörler de çalışma alanına dahil edilmiştir. Barış ise savaşın yokluğu ve varlığı nezdinde tartışılmıştır. 
Ancak sosyolog Johan Galtung'un 1960'larda yazdığı bilimsel metinlerle birlikte barış artık başka bir kuramsal temelde de tartışılmaya başlanmıştır. Barış çalışmalarının öncü isimlerinden biri olarak da kabul edilen Galtung barışı savaşın değil şiddetin varlığı ve yokluğu üzerinden tartışmaktadır. Bu yeni kuramsal eksende barış farklı bir sınıflandırmaya da tabi tutulmaktadır. Buna göre büyük gruplar arasındaki kolektif şiddetin ortadan kalktığ1 duruma negatif barış (çatışmasızlık hali), tamamen barışçıl araçların hakim olduğu ve barışın toplumsallaştığı duruma ise pozitif barış denir. Pozitif barış döneminde fiziksel, kültürel ve yapısal şiddet ortadan kalkar ve toplumsal düzen müthiş bir uyum içinde işler (Galtung, 1967; Galtung, 1969). Fiziksel şiddet, çıplak şiddetin ta kendisidir; yapısal şiddet, kaynaklara erişimdeki eşitsizlik gibi, içinde derin çelişkiler barındıran ve iktidarı iktidar kılan şiddettir. Kültürel şiddet ise yapısal şiddeti meşrulaştıran ve varlığımızın sembolik alanında ortaya çıkan şiddettir (Galtung, 1990). Literatüre yapılmış olan bu kuramsal katkılar Journal of Peace Research'te yayınlanan 1969 tarihli Violence, Peace and Peace Research ile 1990 tarihli Cultural Violence isimli makalelerde ortaya konulmuştur. Galtung Cultural Violence adlı makalesinde, barış çalışmalarının kültürel şiddet ve onun evrimiyle ilgili sistematik bilgiler üretmesi gerektiğini (ama üretilmediğini), çünkü bunların barışın önündeki en büyük engeller olduğunu belirtmektedir.

Galtung'un yaptığı bu çağrıyı 2000’li yıllarda, özellikle politik psikolojiyle ilgilenen akademisyen ve araştırmacılar sahiplenmiştir. Sembol ve sembolik unsurların kullanımının çatışma ve barış üzerindeki etkileri farklı metodolojik yaklaşımlarla sınanmış ve konuya dair literatüre yeni bilgiler sunulmuştur, sunulmaya devam etmektedir. Kültürel şiddet ve kültürel farklılığa yapılan bu vurgu, barış çalışmalarında yeni bir kavşağın belirmesini sağlamıştır. Bugün artık barış, barışın yokluğu üzerinden kendisine yeni ve özgün bir tartışma alanı 
açmaya çalışmaktadır. Böylece barış, kendinde bir durum olarak değer görmekte ve savaş ya da şiddete referansta bulunulmadan çalışılabilmektedir. Sembol ve sembolik unsurların hafıza ile kurduğu yakın ilişkisi bu yeni tartışma alanına katkı sunar. Örneğin anıtlar, heykeller, marşlar vs. artık sadece geçmişteki çatışmaları hatırlatmamakta, birer rehber görevi de görmektedirler. Daha doğrusu yeni nesillere barışın yokluğunda yaşananları göstererek barışa dört elle sarılması gerektiğini göstermektedir.

\section{Barış Çalışmalarında Üç Kavşak}

Chadwick F. Alger 1989'daki Peace Studies at the Crossroads: Where Else? makalesinde barış çalışmalarının üç kavşağın ortasında olduğunu ifade etmektedir. Ona göre ilk kavşak barış eğitimi, barış araştırması ve barış eyleminin kesişimindedir. İkincisi negatif barış ve pozitif barış arasında; üçüncüsü ise geleneksel barış araştırma metodolojileri ile gelişen yeni hareketler arasındadır. Araştırmacıya göre bu alanda başka yeni kavşakların da bulunması gerekir. Alger'in belirttiği yeni kavşakları aramaya bu çalışma dahilinde bir giriş yapılabilir. Alger, kavşakları kurgularken barış çalışmalarındaki metodolojileri göz önünde bulundurmuştur. Fakat bu çalışmada kavşaklara değerini veren şey barış kavramının hangi karşıtlıklar aracılığıyla tanımlandığıdır. Buna göre üç kavşak belirlenmiştir: İlk kavşakta barış, savaşın yokluğu üzerinden tanımlanmakta (çalışılmakta), ikincisinde şiddetin yokluğu, üçüncüsünde ise barışın yokluğu üzerinden tanımlanmaktadır. Bu kuramsal kavşaklar barış araştırmaları literatürünün gelişim seyrini göstermekte; bu seyir ise literatürün barışı teknik bir mesele olarak görmekten vazgeçtiğini aktarmaktadır. İlk kavşağın kuramsal argümanlarını kullananlar için barış kendinde bir hal değil savaşın varlığıyla tanımlanabilecek bir durumdur. Ancak son kavşakta barış artık savaş veya şiddetle 
anılmamakta, barış kendisi aracılığıyla tanımlanmaktadır. Bu kavşakların her biri algımızdaki paradigma değişikliklerine de denk gelmektedir.

\section{Sembol ve Sembolizmin Yarattı̆̆ı Yeni Ŭgrak}

Yukarıda değinildiği üzere Galtung barış çalışmalarındaki en elzem uğraşlardan birinin kültürel şiddete dair bilimsel ve sistematik bilgilerin literatüre kazandırılması gerektiğini vurgulamaktaydı. Çünkü sadece strateji ve taktiklerle yürütülen bir mesele olarak ele alınamayacak olan barışın önündeki engelleri ortadan kaldırmak için kültürel olanı da dikkate almak zorundayı. Yani sembolleri, ritüelleri, duyguları ve uzun yıllar boyunca sosyal bilimlerde gerçeküstü bir alana hapsedilen kavram ve meseleleri sorunsallaştırmak zorundayız ki, alternatif bilgiler üretilebilsin. Esasında çatışma çözümü ve barış yapımı ile ilgili araştırma yapan bilim insanları duyguları ve bilgiyi harekete geçirip manipüle edebilen sembol ve ritüellerin barış inşasındaki rolünü yıllarca gözardı etmişlerdir. Fakat 1990'larda gerçekleşen barış süreçlerinin çoğu başarılı geçtiği halde (müzakereler bir barış anlaşmasıyla sonuçlanmıştır) çatışma potansiyel olarak varlığını devam ettirmiş ve en ufak bir sembolik krizde çatışma eskisinden daha yoğun bir şekilde devam etmiştir. Buna dair en çarpıcı örnekler Kuzey İrlanda'nın bayrak ve geçit törenleri anlaşmazlıklarıdır. Kültürel olanın çatışma ve barış süreçlerinde etkili olması barış çalışmalarıyla ilgilenen araştırmacıların ilgilerini de art alan olarak değerlendirilen kültürel alana kaydırmıştır. Nasıl oluyor da ortak müştereklerde biraraya gelmeyi kabul etmiş olan toplumlarda çatışma devam edebiliyor sorusunun cevabı barış çalışmalarında alternatif bir güzergahı mümkün kılmıştır. Bu güzergahın temel kuramsal nesnesi olan sembol, geçmişle kurabildiği bağlantı sayesinde kuşaklar arasındaki iletişimi sağlamakta, toplumsal hafızaya ve ideolojinin somutlaşmasına 
aracılık etmekte ve duyguları harekete geçirerek kitlelerin ortaklaşabileceği tepkileri ortaya çıkarabilmektedir. İktidarlar sembolleri politik saiklerle kullanarak kitleleri mobilize etmekte ve kendi amaçları doğrultusunda istedikleri bilgiyi manipüle edebilmektedir. Ayrıca iktidar sahibi, semboller aracılığıyla hiçbir söze başvurmadan toplumla diyalog kurabilmekte (Deringil, 2009) ve hedef kitlenin bakıp görmesini sağlayarak kendisine biat edilmesini (Sennett, 2012) kolaylaştırmaktadır. Yani sembol ve sembolik unsurlar toplumla siyaset arasındaki önemli aracılardan biridir. Dolayısıyla David Kertzer'in (1988) de belirttiği gibi sembol ve sembolizm reel politiğin bir taklidi değil tam tersine politiği kuran ve yeniden üreten önemli bir birimdir. Hem kültürel hem de siyasal bir birim olan sembol, çatışma ve barış süreçlerinde oluşturulan politikalara da dahil edilir. Çünkü çatışma ve barışma; ortak duygulara hitap eden, onları kutuplaştıran ve hem duygunun hem de bilginin manipüle edilmesine uygun ortamları mümkün kılan durumlardır.

Kültürel sistemi meydana getiren sembol ve sembolik unsurlar çatışma dönemlerinde silahlı şiddeti desteklemek için kullanılırken barış dönemlerinde ise çatışma alanlarına dönüşmektedir. Nitekim bu alanda yapılan çalışmaların büyük bir kısmı bu bilgiyi desteklemektedir. Sembolizm, çatışma ve barışla ilgili özellikle 2000li yıllardan sonra İrlanda merkezli saygın bir literatürün oluştuğunu belirtmek gerekir. Ancak elbette ki Güney Afrika, Bosna-Hersek, İsrail-Filistin ${ }^{3}$ vb. birçok örnek olayla ilgili, farklı ülkelerden ve değişik disiplinlerden birçok araştırmacı tarafından ciddi akademik yayınlar yapılmış ve yapılmaya

\footnotetext{
${ }^{3}$ İsrail ve Filistin arasında şiddetli çatışmalar devam ediyorsa da kısa sürelerden ibaret olan barış görüşmeleri de yapılmıştır. Bu konuyla ilgili yine 2000'lerden sonra çeşitli çalışmalar görülmektedir. Örneğin Robert C. Rowland ve David A. Frank tarafından 2002'de kaleme alınmış olan Shared Land/Conflicting Identity: Trajectories of Israeli \& Palestinian Symbol Use kitabı ile Rachel Hertz Lazarowitz, Abeer Farah ve Tamar Zelniker tarafindan 2013'te Creative Education adlı dergide yayınlanmış olan Expression of Symbols and Their Message of Peace and Conflict in Identity Drawing Map (IDM): Arab and Jewish Students isimli makaledir. Ancak bunların yanı sıra konuyla ilgili başka çalışmalar da mevcuttur.
} 
devam etmektedir. Söz konusu literatürün ilk eserleri 1990’larda yazılmıştır. Alanın önemli yayınlarından biri Johan Galtung tarafindan 1990'da Journal of Peace Research'te yayınlanan Cultural Violence isimli makale, diğeri ise Simon Harrison'un 1995'te Journal of Royal Anthropological Institute dergisinde yayınlanan Four Types of Symbolic Conflict adl makalesidir. Her iki yayın da barış, çatışma ve sembolizmle ilgili literatüre son derece kullanışlı kuramlar hediye etmişlerdir. Bunlar sırasıyla kültürel şiddet ve sembolik çatışma kuramlarıdır. Gail Landsman'ın 1985'te American Anthropologist dergisinde yayınlanan Ganienkeh: Symbol and Politics in an White/Indian Conflict makalesi de 1990'ların ilk çeyreğinde yazıya gelen eleştiriler ve yine Landsman'ın dergiler yoluyla o eleştirilere verdiği cevaplar neticesinde görünür olmuş ve egemenlikle sembol arasındaki ilişkiye vurgu yaparak çatışmalardaki sembolik unsurlara dikkatleri çekmiştir.

Kültürel şiddet daha önce de belirtildiği gibi toplumsal alanı derinden sarsan eşitsizlikleri meşru kılan ve sembolik alanda varlık gösteren bir şiddet türüydü. Bu açıdan da kültürel şiddet bu çalışma açısından kritik bir yerde durmaktadır. Ancak alternatif bir güzergah olarak sembollerin politik kullanımını barış çalışmalarında mümkün kılan en önemli teorik katkı sembolik çatışma kuramıdır. Pierre Boudieu'nun sembolik sermaye dediği şey için girişilen çekişmeye denk düşen sembolik çatışma, Harrison'a göre dört biçim almaktadır: Değerleme, mülkiyet, yaratım ve genişleme(ci). Birbirinin sembollerine saldırma, onları değersizleştirme, prestiji konusunda hemfikir olunanları kendinin kılma, yenilerini üretme veya olan bazılarını siyasal sistemin dışına itme (Harrison, 1995) gibi özelliklerle detaylandırılabilecek bu çekişmelerde temel uğraş sembolik sermayenin tekelini eline almadır. Çünkü sembolik olarak güçlü olan taraf hem kitlesini kolayca ve ustalıkla yönlendirebilir hem de diğer tarafı değersizleştirmeyi başarabilir. Harrison'un bu kuramını 
kullanan Roger Mac Ginty ve Enlirea Bornman gibi araştırmacılar sırasıyla Kuzey İrlanda ve Güney Afrika'daki sembolik çatışmanın barışla ve çatışmayla olan ilişkisini gözler önüne sermektedirler. Mac Ginty 2001 'de Civil Wars dergisinde yayınladığı The Political Use of Symbols of Accord and Discord: Northern Ireland and South Africa adli makalesinde sifir toplamlı (kazan-kaybet) ve pozitif toplamlı (kazan-kazan) anlayışların hakim olduğu örnek ülkelerde barışın sürdürülebilirliği ile sembollerin politik kullanımı arasındaki ilişkiyi irdelemektedir. Buna göre Kuzey İrlanda örneğinde semboller uyuşmazlığı desteklerken Güney Afrika örneğinde uzlaşıyı desteklemektedir. Bornman'in ise alana yaptığı en önemli akademik katk1 2006 y1lında yayınlanan National Symbols and Nation-building in the Postapartheid South Africa isimli makaledir. Araştırmacı Güney Afrika'daki barış sürecinde bayrak, marş, milli spor takımı gibi sembollerin Siyahlar ve Beyazlar arasındaki uzlaşıya yaptığı katkıları bilimsel verilerle ortaya koymaktadır. Hem Mac Ginty hem de Bornman sembollerin siyasal alandaki kullanımının barış çalışmalarında başvurulması gereken etkin birimler olduğunu göstermektedir. Barış süreciyle uyumlulaştırılmayan, yeniden çerçevelendirilmeyen sembollerin barış yapımını ne denli zorlaştırdığı ve barış durumunda yeni ve pozitif sembollerin barışı sürdürülür kıldığı bilgisi bu çalışmaların literatüre dahil ettiği yeni bilgilerdendir.

Sembol ve ritüellerin barış süreçlerinde ve çatışmalardaki rollerini inceleyen ve bu konuda yeni soruların oluşmasını sağlayan isimlerden biri de uzun yıllar boyunca BM'nin arabulucuları arasında yer alan Lisa Schirch'tür. Ritual and Symbols in Peacebuilding (Barış İnşasında Sembol ve Ritüel) isimli kitabında arabuluculuk deneyimlerini aktaran Schirch'e göre (2005) barış yapımıyla uğraşanların çatışmayı kalıcı bir şekilde çözememesinin sebebi sembol ve ritüellerin etkilerini görmezden gelmeleridir. Çünkü ona göre bu unsurlar, 
anlaşmazlık yaşayan grupları yakınlaştırır ve iletişim kurabilir hale getirir. Araştırmacı belli bazı sembolik edimlerin barışmayı kolaylaştıran dramalar olduğunu savunur. Üstelik bu edimler, karmaşık mesajların çok daha kolay bir şekilde anlaşılmasını mümkün kılar ve insanların dünya görüşlerini, kimliklerini ve ilişkilerini oluşturur ve dönüştürür. $\mathrm{Bu}$ araştırmacı sembol ve sembolik unsurların insanlar üzerinde ciddi etkilere sahip olduğunu ve bunların barış yapımında kesinlikle dikkate alınması gerektiğini düşünmektedir. Schirch'ün kitabında dile getirilen tanıklıklar bize bu güzergahın yeni bilgileri mümkün kıldığını ve üstelik kalıcı barışın inşasında 1srarlı olan barış yapıcılarının bu güzergahı takip etmesi gerektiğini göstermektedir.

Scott L. Moeschberger ve Rebekah A. Philips DeZalia'nın editörlüğünü yaptığı 2014 tarihli Symbols that Bind, Symbols that Divide: A Semiotics of Peace and Conflict adl çalışma da şiddet sonrası dönemde olup uzlaşmaya dönük düzenlemeler gerçekleştiren örnek olaylarda, ayrıştıran ve birleştiren sembollerin barış ve çatışmada edindikleri rollere odaklanmaktadır. Moeschberger ve DeZalia'ya göre (2014) çatışma analizi yaparken bu unsurlara yakından bakmak gerekir. Çünkü sembollerin insanlarda ortaya çıkardığı duygusal tepkiler çatışma ve barış süreçlerinde çok önemlidir. Açığa çıkan duygular bir tarafın kendiyle gurur duymasını ve ait hissettiği grupla iletişim kurmasını güçlendirirken aynı tarafın diğerlerinden nefret etmesine ve onlardan intikam almasına sevk edebilir. Bu tarz güçlü duygusal karşıtlıklar ise biz ve onlar dikotomisini sağlamlaştırmaya hizmet eder. Nesilden nesile aktarılan duyguları ve travmaları her an hissedilir kılan sembol ve sembolik unsurlar, barış dönemlerinde farklı bir bağlamda yeniden çerçevelendirildiğinde bu defa insanları birleştiren bir formda hareket edebilir. 
Duygu politikasına dair önemli ipuçları veren sembol ve sembolizm konusunu barış ve çatışmayla harmanlayan İrlanda ve Afrika literatürü bu tartışma alanının temelinde yer almaktadır. Çünkü Kuzey İrlanda ve Güney Afrika deneyimleri bu konudaki en verimli örneklerdir. Her iki barış sürecine de sembol ve sembolik unsurların rolü damgasını vurmuştur. 1990'lardan önce barışın sembolleri nelerdir sorusu üzerinden yapılan tartışmalar 90’lar ve özellikle 2000'lerden sonra barış süreçlerinde sembollerin kullanımı ve etkileri nelerdir gibi bir soruya evrilmiştir. Böylece aslında Galtung'un pozitif barış dediği barışın sürdürülebilmesi ile semboller arasındaki ilişki irdelenmeye başlamıştır. Ayrıca bugünlerde özellikle duygulara odaklanmış olan bu literatür, yeni ve alternatif çalışmaların varlığına da ihtiyaç duymaktadır.

\section{SONUÇ YERINE}

Siyasal olanı cisimleştiren, temsil eden ve kodlayan siyasal semboller, anlaşmazlık yaşayan gruplar arasında gerginlik sebebi olabilmekte veya uzlaşıyı sağlayan araçlara dönüşebilmektedir. Bu durumda barış yapımı ve çatışmada da bu birimler çok kritik roller alabilirler. Böylesi kültürel birimlerin sahip olduğu bu güç, barış çalışmalarıyla ilgilenen bilim insanlarının da ilgisini çekmiş ve özellikle 2000'li yıllardan sonra politik psikolojinin argümanları eşliğinde sembol ve sembolik unsurlar barış araştırmalarındaki yerini almıştır. Her geçen gün sayısı artan araştırmalarla birlikte barış çalışmalarında alternatif bilgiler üretilmekte ve barış artık sadece teknik bir mesele olarak ele alınmamakta, kültürel olan da örneğin duygular da- hesaba katılmaktadır. Yine bu güzergahta barışın farklı bir temelde tanımlanmasına da rastlanmaktadır. Buna göre barış artık savaşın veya şiddetin yokluğuyla değil bizzat barışın yokluğuyla yani kendisiyle karşılaştırılmakta ve öyle tanımlanmaktadır. 


\section{KAYNAKÇA}

Akgül, N.S.P. (2016, 08 Mart). Barış çalışmaları: Başlangıçtan Günümüze Değişimi. https://www.researchgate.net/publication/293799826. Erişim Tarihi: 20 Eylül 2017.

Alger, C.F. (1989). Peace Studies at the Crossroads: Where Else?. The Annals of the American Academy of Political and Social Science. 504. 117127.

Alger, C.F. (2007). Peace Studies as a Transdisciplinary Project. Handbook of Peace and Conflict Studies içinde. Charles Webel ve Johan Galtung (Ed.). Londra ve New York: Routledge.

Bornman, E. (2006). National Symbols and Nation-building in the Post-apartheid South Africa. International Journal of Intercultural Relations. 30. 383-399.

Boulding, K.E. (1978). Future Directions in Conflict and Peace Studies. The Journal of Conflict Resolution. 22/2. 342-354.

Dungen, P. V. D.; Wittner, L. S. (2003). Peace History: An Introduction, Journal of Peace Research. 40(4). 363-375.

Deringil, S. (2009). Simgeden Millete: II. Abdülhamid'den Mustafa Kemal'e Devlet ve Millet. İstanbul: İletişim Yayınları.

Fahey, J. J. (2010). Peace Studies: Beginning and Development, The Oxford International Encyclopedia of Peace içinde. Nigel J. Young (Ed.), Vol.3, Oxford University Press.

Galtung, J. (1969). Violence, Peace and Peace Research. Journal of Peace Research. 6 (3). 167-191.

Galtung, J. (1990). Cultural Violence. Journal of Peace Research. 27 (3). 291-305.

Harrison, S. (1995). Four Types of Symbolic Conflict. Journal of Royal Anthropological Institute. 1(2), 255-272.

Lazarowitz, R.H., Farah, A., Zelniker, T. (2013). Expressions of Symbols and their Message of Peace and Conflict in Identity Drawing Map (IDM): Arab and Jewish Students. Creative Education. 4(7A2). 137-143.

Mac Ginty, R. (2001). The Political Use of Symbols of Accord and Discord: Northern Ireland and South Africa. Civil Wars. 4(1), 1-21.

Mac Ginty, R. (2003). The Roles of Symbols in Peacemaking. John Darby ve Roger Mac Ginty (Ed.) Contemporary Peace Making: Conflict, Violence and Peace Processes içinde. (s.235-242). UK: Palgrave Macmillian.

Mason, G.H. (2002). Peace Studies in the Next Half -Century. Peace Review. 14/1. 15-19.

Moeschberger, S.L.; DeZalia, R.A.P. (Ed.) (2014). Symbols That Bind, Symbols That Divide: The Semiotics of Peace and Conflict. Switzerland: Springer International Publishing.

Rowland, R.C., Frank, D.A. (2002). Shared Land/Conflicting Identity: Trajectories of Israeli and Phalestinian Symbol Use. East Lansing: Michigan State University Press.

Sandıklı, A., Kaya, E. (2012). Çatışma Çözümü ve Türkiye'de Kürt Sorunu. BİLGESAM Rapor No:45, İstanbul.

Schirch, L. (2005). Ritual and Symbol in Peacebuilding. Bloomfield: Kumarian Press. 
Sennett, R. (2014). Ten ve Taş: Batı Uygarlığında Beden ve Şehir. (10. Basım).T. Birkan (Çev.). İstanbul: Metis Yayınları.

Yılmaz, M.E. (2006). Uyuşmazlık Analizi ve Çözümü: İnsan Uyuşmazlıklarının Kaynakları ve Çözüm Paradigmaları. Ankara: Nobel Yayın Dağıtım. 